\title{
Probabilistic modeling of crack growth in large structures
}

\author{
Yury Izvekov*, Olga Torshina, Alexander Anisimov, Galina Kameneva, and Tatyana \\ Bondarenko \\ Department of Applied Mathematics and Informatics, Nosov Magnitogorsk State Technical \\ University, Magnitogorsk, Russia
}

\begin{abstract}
The allowance for various defects including cracks represents a critical issue related to structural risk analysis. The complexity and the ambiguity involved with such allowance for the amount and growth of defects (cracks) is demonstrated on the real structure of a metallurgical overhead crane. The problem of distribution function conversion must be solved to allow for any variations in defects starting from the point of time when the initial (technological) defectiveness is determined and ending with the estimated time of risk analysis. Due to the lack of data on cyclic resistance to cracking for Вст3 3 तn 5 steel, it does not yet seem possible to construct the distribution functions and to determine the estimated theoretical average and dispersion of crack sizes. However, by using the previously obtained calculated data on active stresses and strains, it is now possible to simulate growth of cracks based on Weibull distribution. Different engineering solutions can be accepted at various stages of operating large structures, according to the obtained results.
\end{abstract}

\section{Introduction}

The allowance for crack growth in various fracture models represents quite a critical issue related to structural risk analysis [1-7]. The triggering factors can include both technological defects and structural concentrators or material nonhomogeneities. In the former case, the probability density function $f_{V}(l)$ of sizes of defects existing in a particular object varies with time whereas in the latter case both density $f_{V}(k)$ and $f_{V}(l)$ vary as new cracks may arise.

The following problem of defect distribution function conversion must be solved to allow for such variations [2]:

$$
\begin{aligned}
f_{V}\left(k, t_{0}\right) & \rightarrow f_{V}(k, t), \\
f_{V}\left(l, t_{0}\right) & \rightarrow f_{V}(l, t),
\end{aligned}
$$

where $t_{0}$ is the point of time for which the initial or technological defectiveness is determined;

$t$ is the estimated time of risk analysis.

\footnotetext{
*Corresponding author: yurij.izvekov@mail.ru
} 


\section{Research materials and methods. discussion}

The current analysis of different literature sources is unable to provide a proper solution to the posed problem. The main objectives of researchers and engineers include the simulation of random paths of changes in the size of a single crack at random loading and the estimation of probability distribution functions for such sizes at a certain point of time or length of structural life left before the specified crack size $l$ is achieved.

When solving the problem of density forecasting $f_{V}(l, t)$, it is enough to determine the statistical estimates of the average value $m_{l}(t)$ and the dispersion $D_{l}(t)$ of sizes of defects and cracks.

The above-mentioned estimates can be obtained based on the assumed parametric model of potential fracture zone [2] by using the method of statistical simulation of crack kinetics based on empirical relationships. Paris' or Foreman's equation is used for this purpose as follows:

$$
\begin{gathered}
\frac{d l}{d N}=C(\Delta K)^{n}, \Delta K=\Delta \sigma \sqrt{\pi l \varphi(l)} \\
\frac{d l}{d N}=\frac{C(\Delta K)^{n}}{(1-r) K_{c}-\Delta K}
\end{gathered}
$$

where $\Delta \sigma$ is the stress amplitude;

$\varphi(l)$ is the function dependent on physical dimensions of the cracked structural element;

$r$ is the assymetry factor of the loading cycle;

$K_{c}$ is the performance of static resistance to cracking; and

$C$ and $n$ are the performances of cyclic material resistance to cracking.

When the statistical data on parameters $\sigma, l, K_{c}, C$ and $n$ are given, the statistical estimates of the average value $m_{l}(t)$ and the dispersion $D_{l}(t)$ of sizes of defects and cracks can be obtained by means of N-time implementation of the model (3) or (4).

We shall examine the growth of cracks in truss webs of the load-bearing structure of a metallurgical overhead crane with 300 ton lifting capacity, 24 meter span and 3 meter height [5]. The original loading diagram is presented in figure 1.

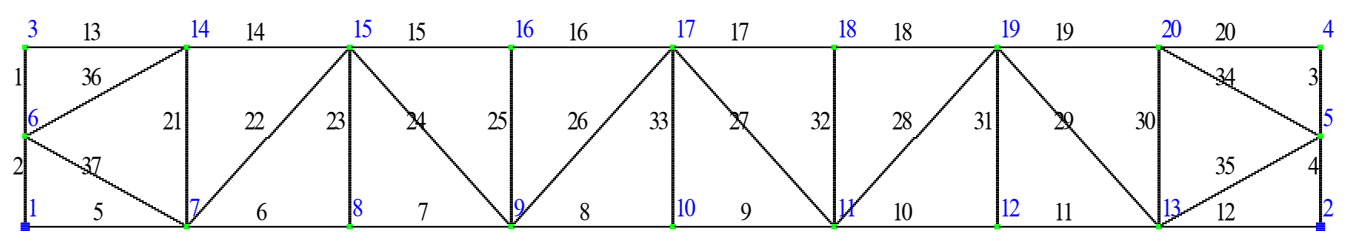

Fig. 1. Original diagram.

Truss material: structural steel Вст3сп5. LIRA-SAPR software package was used for truss analysis [8,9]. $\Delta \sigma=50-100 \mathrm{MPa}$ (megapascals). Data on varying stresses in the truss webs were obtained [5].

Given that $\Delta K<K_{f c}$, the crack will grow and the operational life of this load-bearing structure can be calculated as follows:

$$
N=10^{-7} \int_{l_{0}}^{l_{c}}\left(\frac{K_{f c}}{\Delta K}\right)^{n} d l
$$


Unfortunately, we were unable to determine the performances of cyclic resistance to cracking for Встзсп5. Given that the metallurgical overhead crane with 300 ton lifting capacity is operated under heavy- and superheavy-duty conditions and the total number of cycles over a 15 -year warranty service life is $2.34 * 10^{7}[2,5]$, the integral distribution function of crack growth in the webs of the load-bearing structure under the active stresses and strains can be simulated. We shall apply the Weibull distribution [10 ]:

$$
F(l)=1-e^{-\left(\frac{l}{\beta}\right)}, l \geq 0 .
$$

Simulation results are presented in figure 2 .

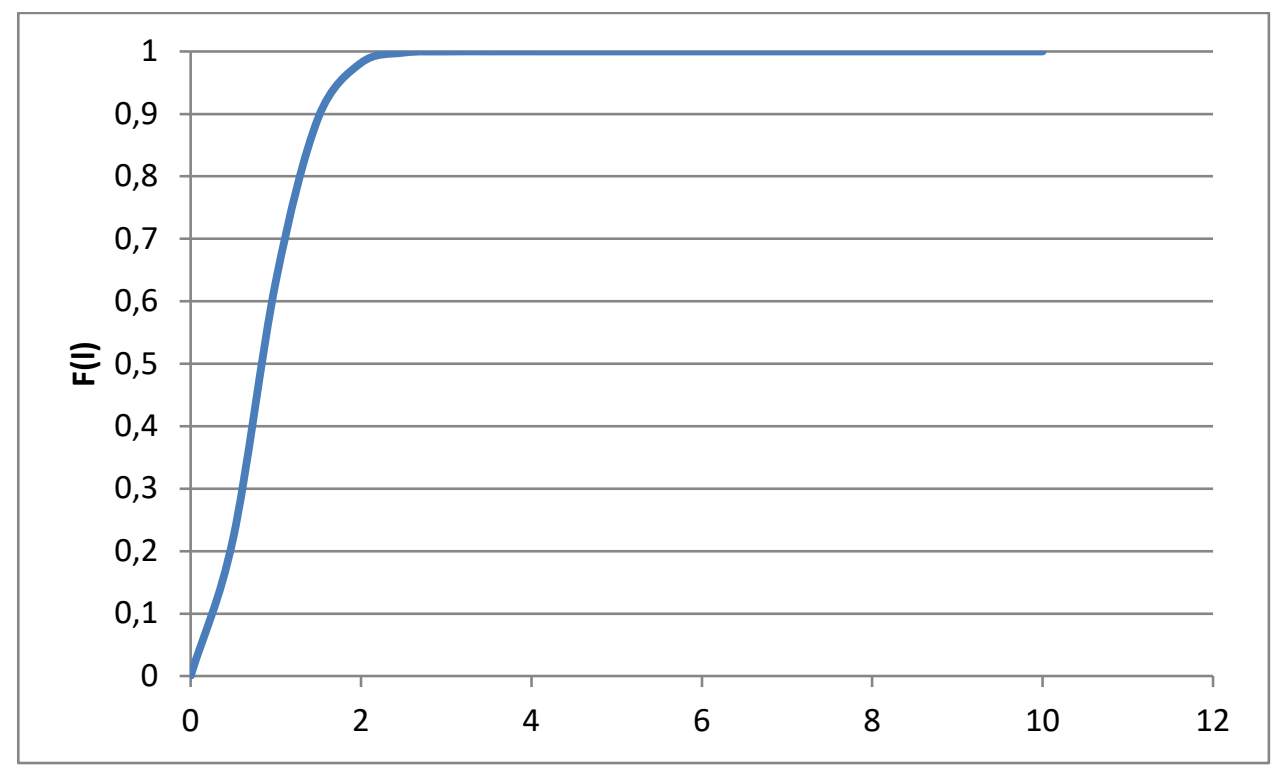

Fig. 2. Distribution function of crack growth under the active stress

We can see that under such conditions, stresses and strains existing during the warranty and the postwarranty service life of these structures the growth in the number of cracks is very likely inevitable. This imposes strict requirements and limitations. It is assumed that the initial size of crack at the web connection is $10 \mathrm{~cm}$ (centimeters). We shall consider a 1 $\mathrm{m}$ (meter) crack as a critical size for a structure. Such cracks are often seen in a real-case scenario.

\section{Conclusions}

Resistance to cracking in large structures is a serious issue. The allowance for the amount and the sizes of various defects and cracks represents an important scientific-and-technical problem.

The existence of both technological (initial) and operational defectiveness is assumed for large and span structures. The occurrence of defects and cracks may not constitute a hazard by itself. A group of different complementary factors contributing to fracturing is normally needed to start the fracture process. These can include sensitivity of structure material to stress concentration, the level of element loading, the pattern of load 
application, ageing and cold-work hardening, operating temperature and structural joint rigidity.

Probabilistic simulation of crack growth in the potential fracture zone of a metallurgical overhead crane, i.e. the truss of the load-bearing structure, must include defect probability density functions allowing for the time of risk analysis.

Due to the lack of data on cyclic resistance to cracking for structural steel, it is currently impossible to construct defect and crack distribution density functions for such structures.

However, calculated data on active stresses and strains allow to simulate crack growth using Weibull distribution and the obtained data adequately conform to the performance data.

Therefore, this information allows to perform hazard analysis for structures of different applications.

Engineers, researchers and operating staff will understand what scientific-and-technical decisions must be made during design, operation, the assessment of technical condition and lifetime and expert examination of large structures.

\section{References}

1. Yu.A. Izvekov, O.A. Torshina, Mathematical simulation of reliability, safety and risk indicators associated with equipment components existing at a steel plant, IOP Conference series: Material science and engineering, IOP Publishing, 687, 6, P. 066008 (2019)

2. K.V. Frolov, N.A. Makhutov, Bezopasnost Rossii. Pravovye, sotsialno-ekonomicheskie i nauchno-tekhnicheskie aspekty (Safety of Russia. Legal, Socio-economic, and Scientific and Technical aspects), In 4 Parts, Part 1: The Basic Concepts of the Analysis and Regulation of Safety, Znanie, Moscow (2006)

3. G. Taguchi, Quality Engineering in Japan, Bull. Japan Soc. Precis. Eng. 4, pp. 237-242 (1985)

4. D.B. Hammad, N. Shafiq, M.F. Nuruddin, Criticality Index of Building Systems Using Multi-Criteria Decision Analysis Technique, MATEC Web of Conferences, EDP Sciences 15:01018 (2014)

5. Yu.A. Izvekov, V.V. Dubrovsky, A.L. Anisimov, Dynamic pattern of safe operation indicators for heavy machines, International conference on industrial machine building, Springer, Cham, pp. 595-601 (2020)

6. H. Kumamoto, E.J. Henley, Probabilistic Risk Assessment and Management for Engineers and Scientists, IEEE Press, New York (1996)

7. A.M. Lepikhin, Risk analysis of designs of potentially dangerous objects on the basis of probability models of mechanics of destruction, Dissertation, RAS, Siberian office, institute of computing model operation, Krasnoyarsk (2000)

8. SP 16.13330 2011, Steel structures, Updated version of SNiP II-23-81

9. SP 20.13330 2011, Loads and actions, Updated version of SNiP 2.01.07-85

10. W.A. Weibull, A statistical theory of the strength of material, Report № 151, Ingeniors Vetenskaps Akademiens Handligar, Stockholm (1939) 